\title{
Study of COVID Pandemic in Selected High Burden Countries in the World
}

\author{
Ramakrishna Rachakonda ${ }^{1}$, Abdul Waseem Shaik ${ }^{2}$, Umar Pasha Shaik ${ }^{3}$, \\ Nagarjuna Reddy Sunkara ${ }^{4}$, Seenu Ayyakannu ${ }^{5}$
}

1,2, 3, 4, 5 Department of Pulmonology, NRI Medical College, Chinnakakani, Guntur, Andhra Pradesh, India.

\section{ABSTRACT}

\section{BACKGROUND}

COVID 19 pandemic affected the whole world resulting in the death of more than four million of population throughout the world and it is nothing less than a world war. Nearly 223 countries are affected. With the understanding of the pathology changes were introduced in the treatment of COVID-19 disease. Vaccines came for the public use in different countries in January 2021. Though there is an impact of the vaccines in most of the countries, coverage has not reached significant proportions in the world. Despite vaccination number of people infected in high burden countries is still high with corresponding increase in the mortality rate. Here we have made an attempt to compare the statistics in different countries along with global figures. Control of COVID pandemic probably depends upon a combination of awareness of disease among people, COVID appropriate behaviour, vaccination for COVID and isolation of patients with disease and appropriate treatment of the COVID patients.

We collected information on COVID from Worldometer and WHO publications and compared the results from selected high burden countries

COVID affected nearly all the countries in the world. We have presented the cases/day and deaths per day in the selected countries at different times of the pandemic from February 2020 to October 2021. Some countries like USA, India, Brazil, UK, Russia, France and Turkey are affected more than others. $19 \%$ of the cases in the world are reported in USA and $14 \%$ of cases in India. Even after good vaccine coverage, UK, USA and Russia are reporting significant COVID-19 cases. All over the world more than 245 million people are affected from COVID 19 with a mortality rate of $2.03 \%$. Brazil and Russia have a high mortality rate of around $2.80 \%$.

Continued appearance of new cases in certain countries is probably because of the new variants.

\section{KEY WORDS}

COVID 19, Vaccination, Variants of Concern (VOC), Mutations, SARS, MERS
Corresponding Author: Dr. Ramakrishna Rachakonda, Sanjeevani Clinic, A1, Ramkuteer Majestic, $3^{\text {rd }}$ Line, $13^{\text {th }}$ Cross Road, Brodipet, Guntur-522002, Andhra Pradesh, India.

E-mail:ramakrishna45@yahoo.co.in

DOI: $10.14260 / j e m d s / 2021 / 813$

How to Cite This Article:

Rachakonda R, Shaik AW, Shaik UP, et al. Study of COVID pandemic in selected high burden countries in the world. J Evolution Med Dent Sci 2021;10(45):4027-4031, DOI: 10.14260/jemds/2021/813

Submission 15-10-2021,

Peer Review 25-11-2021,

Acceptance 01-12-2021,

Published 31-12-2021.

Copyright (C) 2021 Ramakrishna Rachakonda et al. This is an open access article distributed under Creative Commons Attribution License [Attribution 4.0 International (CC BY 4.0)] 


\section{BACKGROUND}

COVID 19 disease after its origin from Wuhan city of Hubei province of China spread to Europe initially and later to more than 220 countries in the world. People have migrated to different parts of the world in search of employment. Initially the disease extended to northern Italy from leather workers of Chinese origin and caused extensive mortality challenging the medical infrastructure. The mortality was high during the first wave of the disease in February 2020. Initially the pathogenesis of the disease and treatment modalities were not defined since the virus was new and no specific antivirus was available. Initial treatment modalities were based on the experience of SARS virus and MERS virus epidemic experience.

Post-mortem studies done in Italy revealed that severe inflammation of lungs because of cytokine storm, vascular inflammation and thrombosis of smaller vessels were responsible for the respiratory failure and multiorgan failure associated with coronavirus disease. The utility of antiinflammatory drugs, corticosteroid therapy, anticoagulants anti cytokine drugs improved the prognosis.

Later onset of first wave of COVID-19 in India after lockdown measures were strictly implemented and awareness of the pathology of the disease relatively decreased the mortality in India despite heavy burden of cases and poor medical infrastructure compared to the western world.

COVID-19 virus pandemic behaved differently in different parts of the world. In countries like UK and USA there were multiple waves of the disease which continued unabated even today. The main reason is because of the new variants. There is a difference in the wave pattern of the disease in the year 2020 and 2021. In the year 2020, vaccines were not available. From early 2021, messenger RNA virus vaccines of Pfizer, Moderna, adeno virus vector vaccines and whole virus vaccines were made available in different parts of the world. The Governments made extensive efforts in administration of vaccines. Vaccines associated with new anti-viral drugs; availability of monoclonal antibodies improved the prognosis. What puzzled the world is the fact that people who got vaccinated with 2 doses also got infected. But the severity of the disease is considerably less among the vaccinated and mortality is also is less. In USA a booster dose of vaccination is also advised.

Despite vaccination the new variants of COVID 19 have caused repeated infections particularly in Russia, UK and USA where the incidence of new cases is still high as on the last week of November 2021. B.1.1.529 South African variant also called as Omicron variant is presently a cause of concern throughout the world and an alert has been issued by the World health Organization.

\section{METHODS}

We have analysed the pattern of COVID 19 pandemic in selected high burden countries in the world from authenticated data from World Health Organization, worldometer and Government of India portals and compared the results.
Analysis of the total number of cases and percentage of deaths showed that nearly $19 \%$ of cases were diagnosed in the United States of America and $14 \%$ in India. Brazil and Russia have relatively higher mortality rates. Recovery rates are high in India, Brazil, France and Turkey because incidence of new cases has declined in these countries at the time of writing of this article. Recovery rates are around $80 \%$ in USA, Russia and UK because of increase in new cases in these countries.

Death rate among COVID patients is variable in different countries and in different provinces of the same country. While the overall death rate is $2.03 \%$ globally, death rates in USA, UK and France are comparable and less than the global death rate. Indian death rate among COVID patients is $1.33 \%$ and Turkey showed a much lower death rate of $0.88 \%$. Brazil and Russia have consistently higher death rates. It is difficult to explain this variation. Racial variation in transmissibility, ability to cause inflammation in lungs and other organs, affinity of the virus to ACE2 receptors may be different in different nations.

High prevalence of the disease in USA may be explained by increased awareness among the population and increased number of RT PCR tests conducted.

\begin{tabular}{|cccccc|}
\hline Country & $\begin{array}{c}\text { Total No. } \\
\text { of Cases }\end{array}$ & $\begin{array}{c}\text { Total No. } \\
\text { of Deaths }\end{array}$ & $\begin{array}{c}\text { \% of } \\
\text { Deaths }\end{array}$ & $\begin{array}{c}\text { Total No. } \\
\text { of Cases } \\
\text { Recovered }\end{array}$ & $\begin{array}{c}\text { \% of } \\
\text { Recovery }\end{array}$ \\
\hline World & $245,794,470$ & $4,987,925$ & $2.03 \%$ & $222,796,225$ & $90.64 \%$ \\
USA & 46,597003 & 761856 & $1.63 \%$ & $36,476,756$ & $78.28 \%$ \\
Brazil & $21,766,168$ & 606,726 & $2.78 \%$ & $20,965,296$ & $96.32 \%$ \\
India & $34,231,809$ & 456,418 & $1.33 \%$ & $33,614,434$ & $98.20 \%$ \\
\hline UK & $8,897,149$ & 140,041 & $1.57 \%$ & $7,232,313$ & $81.29 \%$ \\
\hline Russia & $8,352,601$ & 233,898 & $2.80 \%$ & $7,242,735$ & $86.71 \%$ \\
\hline Turkey & $7,936,007$ & 69,769 & $0.88 \%$ & $7,376,821$ & $92.95 \%$ \\
\hline France & 7160538 & 117671 & $1.64 \%$ & $6,938,840$ & $96.90 \%$ \\
\hline \multicolumn{5}{|c|}{ Table 1. Number of Cases, Deaths and Recoveries in Countries } \\
\hline
\end{tabular}

\begin{tabular}{|c|c|c|c|c|c|}
\hline Country & $1^{\text {st }}$ Peak & $2^{\text {nd }}$ Peak & $3^{\text {rd }}$ Peak & $4^{\text {th }}$ Peak & $5^{\text {th }}$ Peak \\
\hline USA & $\begin{array}{c}\text { April } 2020 \\
34943 \\
\text { cases/day } \\
2722 \\
\text { Deaths/day }\end{array}$ & $\begin{array}{c}\text { July } 2020 \\
77043 \\
\text { cases/day } \\
1440 \\
\text { Deaths/day }\end{array}$ & $\begin{array}{c}\text { January } 2021 \\
305956 \\
\text { cases/day } \\
4450 \\
\text { Deaths/day }\end{array}$ & $\begin{array}{c}\text { August } 2021 \\
196096 \\
\text { Cases/day } \\
2646 \\
\text { deaths/day }\end{array}$ & \\
\hline India & $\begin{array}{c}\text { Sep } 2020- \\
97857 \\
\text { Cases/day, } \\
1287 \\
\text { deaths/day }\end{array}$ & $\begin{array}{c}\text { April 2021- } \\
412618 \\
\text { cases/day, } \\
4967 \\
\text { deaths/day }\end{array}$ & & & \\
\hline Brazil & $\begin{array}{c}\text { July } 2020- \\
71265 \\
\text { cases/day-1554 } \\
\text { deaths/day }\end{array}$ & $\begin{array}{c}\text { Jan } 2021- \\
87787 \\
\text { cases/day, } \\
1455 \\
\text { deaths/day }\end{array}$ & $\begin{array}{c}\text { March 2021- } \\
98217 \\
\text { cases/day- } \\
4211 \\
\text { deaths/day }\end{array}$ & $\begin{array}{l}\text { June } 2021- \\
115041 \\
\text { cases/day, } \\
2760 \text { deaths } \\
\text { /day }\end{array}$ & \\
\hline UK & $\begin{array}{c}\text { April 2020- } \\
7845 \\
\text { cases/day-1169 } \\
\text { deaths/day }\end{array}$ & $\begin{array}{c}\text { Nov 2020- } \\
33403 \\
\text { Cases/day - } \\
697 \\
\text { deaths/day }\end{array}$ & $\begin{array}{c}\text { Jan } 2021- \\
67794 \\
\text { cases/day, } \\
1824 \\
\text { deaths/day }\end{array}$ & $\begin{array}{c}\text { July } 21-54194 \\
\text { cases/day-49 } \\
\text { deaths/day }\end{array}$ & $\begin{array}{c}\text { October } \\
21-57427 \\
\text { Cases/day- } \\
263 \\
\text { deaths/day }\end{array}$ \\
\hline Russia & $\begin{array}{c}\text { May 2020- } \\
11656 \\
\text { Cases/day, } 232 \\
\text { Deaths/day }\end{array}$ & $\begin{array}{c}\text { Dec 2020- } \\
29935 \\
\text { Cases/day- } \\
635 \\
\text { deaths/day }\end{array}$ & $\begin{array}{c}\text { July 2021- } \\
25766 \\
\text { Cases/day- } \\
787 \\
\text { Deaths/day }\end{array}$ & $\begin{array}{c}\text { October 2021- } \\
40993 \\
\text { Cases/day- } \\
1158 \\
\text { deaths/day }\end{array}$ & \\
\hline Turkey & $\begin{array}{c}\text { April 2020- } \\
13976 \\
\text { Cases/day, } \\
\text { 127 Deaths/day }\end{array}$ & $\begin{array}{c}\text { December } \\
2020-33736 \\
\text { Cases/day, } \\
256 \\
\text { deaths/day }\end{array}$ & $\begin{array}{c}\text { April 2021- } \\
62797 \\
\text { Cases/day, } \\
394 \\
\text { Deaths/day }\end{array}$ & $\begin{array}{c}\text { October 2021- } \\
33860 \\
\text { Cases/day, } 248 \\
\text { Deaths/day }\end{array}$ & \\
\hline France & $\begin{array}{c}\text { April 2020- } \\
4755 \\
\text { Cases/day, } \\
1437 \\
\text { deaths/day }\end{array}$ & $\begin{array}{c}\text { November } \\
\text { 2020-83324 } \\
\text { cases/day, } \\
932 \\
\text { Deaths/day }\end{array}$ & $\begin{array}{c}\text { April 2021- } \\
57127 \\
\text { Cases/day, } \\
431 \\
\text { Deaths/day }\end{array}$ & $\begin{array}{c}\text { August 2021- } \\
30924 \\
\text { Cases/day, } 169 \\
\text { deaths/day }\end{array}$ & \\
\hline & $\begin{array}{r}\text { 2. Peak of } 1 \\
\text { Sel }\end{array}$ & $\begin{array}{l}\text { cidence of } N \\
\text { cted High } \mathrm{Bu}\end{array}$ & $\begin{array}{l}\text { w Cases a } \\
\text { den Count }\end{array}$ & $\begin{array}{l}\text { ad Deaths/1 } \\
\text { ries }\end{array}$ & in \\
\hline
\end{tabular}

The global pandemic started from the last week of February 2020. Slowly the daily cases increased with a peak in January 2021 of 841000 cases /day. After a fall, a higher 
peak of 940000 daily cases occurred in April 2021. Another peak of 746000 new cases /day occurred in August 2021. In the last week of October daily number of cases of 478000 were seen. The pandemic continued due to upsurge of daily cases in Russia, USA and United Kingdom.

The daily deaths globally reached a peak of $17579 /$ day in January 2021. Second peak of deaths corresponded with the number of cases occurred in April 2021 of around 15859. Third peak occurred in the month of August 2021 and amounted to 11,500 cases a day.

In the USA, major peaks of cases occurred in April 2020, January 2021 and September 2021. Daily deaths corresponded with the number of cases. USA saw several peaks of the disease and the biggest peak occurred in January 2021 with more than 300000 cases per day and 4450 deaths/day.

In India, daily new cases peaked in the month of September 2020 and a much higher peak of cases and deaths occurred in April-May 2021. After that the number of cases and deaths decreased and anticipated third wave is yet to be seen. In the second peak during April-May 2021 daily cases increased to more than four lakhs/day and daily deaths to more than four thousand/day. In Brazil the peak of cases and deaths occurred in March-April 2021 and the wave subsided. First peak was seen in Brazil in June-July 2020.

The United Kingdom experienced large number of cases and deaths in January 2021. In October 2021 number of cases per day was over 40000 but the deaths came down to less than 500/day. Russia is experiencing a new wave of cases and deaths in October 2021 after several smaller peaks from April 2020. Turkey experienced several peaks since the onset of the pandemic and significant number of cases and deaths were reported even in October 2021. France experienced several peaks in 2020 and the number of cases and deaths came to steady low by August-September $2021 .^{1}$

\section{Covid Vaccination Status in Different Countries: ${ }^{2}$}

More than 3.88 billion people worldwide have received a dose of a Covid-19 vaccine, equal to about 50.6 percent of the world population.

\begin{tabular}{|ccccc|}
\hline Country & $\begin{array}{c}\text { Total No. } \\
\text { Vaccinated }\end{array}$ & $\begin{array}{c}\text { No. Fully } \\
\text { Vaccinated and } \\
\text { Percentage }\end{array}$ & $\begin{array}{c}\text { At least One } \\
\text { Dose Given and } \\
\text { Percentage }\end{array}$ & $\begin{array}{c}\text { Additional } \\
\text { Dose }\end{array}$ \\
India & 106 Crores & 32.7 Crores -24\% & $70 \%$ & \\
USA & $58 \%$ & $67 \%$ & $5 \%$ \\
Brazil & $56 \%$ & $75 \%$ & $3.5 \%$ \\
UK & $68 \%$ & $75 \%$ & $11 \%$ \\
Russia & $33 \%$ & $38 \%$ & $1.2 \%$ \\
France & $68 \%$ & $76 \%$ & $4.3 \%$ \\
Turkey & $58 \%$ & $66 \%$ & $13 \%$ \\
\hline \multicolumn{4}{c}{ Table 3 Vaccination Status of Different Countries } \\
\hline \multicolumn{4}{c}{} \\
\hline
\end{tabular}

Success of vaccination depends upon the quality of vaccines, number of doses administered, antibody levels and COVID appropriate behaviour on the part of the population. Mortality rate definitely is reduced throughout the world probably because of increased vaccination drive, awareness among people, newer modalities of treatments. However, it is difficult to predict the outcome of COVID disease. Severe disease and high mortality are seen in some patients. ${ }^{3}$

\section{DISCUSSION}

The cause of increased infections and mortality in different countries can be because of mutations in the virus causing variants. On an average, a genome from a virus collected in October 2020 has around 20 mutations compared to the first strain sequenced in January 2020 (Wuhan-Hu-1).4,5 In the UK, the B.1.1.7 variant was first identified as a Variant of Concern in December 2020, it was increasing in frequency during a nationwide lockdown, and other variants were decreasing in frequency. B.1.1.7 variant is currently the most highly sequenced and well-characterized VOC, and it has increased levels of transmissibility at a rate between 40 and $70 \%$ B.1.1.7 variant can give rise to negative PCR test with routine RT PCR test for COVID 19 but has no action on rapid antigen test. ${ }^{7}$ Other variants of concern particularly P.2 variant in Brazil is of interest because it harbours a E484K mutation and the CAL.20C variant in California, with an L452R mutation suggesting increased transmissibility among SARSCoV-2 variants. ${ }^{8}$ B.1.351 variant possesses mutations that enable it to escape immunity from both previous infection and some vaccines. UK, Brazil and South African variants caused increased transmission, reinfection and vaccinations to overcome these mutations may be prepared ${ }^{9}$ because of the variants vaccine efficiency in different populations may differ and may have to be tested in specific population. A twodose regimen of ChAdOx1-nCoV19 did not show protection against mild-moderate Covid-19 due to B.1.351 variant but severity of COVID 19 is decreased.10

In South Africa, the B.1.351 variant causes increased transmissibility and reduces the efficacy of some vaccines. ${ }^{11}$ For B.1.351, there may be some form of enhanced escape from immune pressure and onward transmission, generating a fitness advantage. Mutation present in the variant is important because it can alter its survival, increase transmissibility, alter the diagnostic test and make vaccine ineffective. ${ }^{12}$

In the case of P.1 variant, Japan reported the variant in patients returning from Brazil. ${ }^{13}$ The variant has spike mutations that are also found in the B.1.351 variant: It increases virus binding affinity to the ACE2 receptor on human cells, E484K mutation renders the virus less susceptible to some monoclonal antibodies and K417N/T increases binding affinity to ACE2, in combination with N501Y).

If these mutations occur at primer binding sites or affect the structure of viral antigen targets that are detected by the antigen tests, they have the potential to impact the accuracy of diagnostic tests. ${ }^{11}$ Variants have the ability to alter the diagnosis, increased penetration, increased transmissibility and have effect on the success of vaccination. ${ }^{5}$

The sudden surge in COVID-19 cases in India in April 2021 coincides with high prevalence of more-transmissible variants, associated with diagnostic test failures and antibody escape. These coronavirus SARS-CoV-2 variants of concern B.1.1.7 (501Y.V1), B.1.351 (501Y.V2) and B.1.1.28.1 (501Y.V3; also known as P.1)—were observed during the sudden surge in COVID-19 cases in the UK, South Africa and Brazil, respectively, with subsequent local transmission across the world. The recently designated variant of concern B.1.617 and variant of interest B.1.618 have also been gaining 
attention in India. Variant B.1.617.1 shows co-occurrence of three key mutations in sequence encoding the viral spike protein: L452R, E484Q and P681R. L452R another similar variant of concern, B.1.617.2, with mutations L452R, T478K and $\mathrm{P} 681 \mathrm{R}$, is highly prevalent in Gujarat, India. There was enrichment for the mutation T478K or T478R when SARSCoV-2 was subjected to weak neutralizing antibodies, which indicates this mutation may lead to antibody escape. Variant B.1.618, which has the E484K mutation, is prevalent in the state of West Bengal, Indian new variants cause re-infections, either after natural infection or after vaccination, as observed in Brazil and the United States, respectively. ${ }^{14}$

Vaccination programs aim to control the COVID-19 pandemic. Vaccine effectiveness, coverage and nonpharmacological interventions, physical distancing, hand sanitization and mask use are equally important in controlling the pandemic. ${ }^{15}$ Vaccination reduces the overall infection rate, adverse outcomes particularly in patients above 65 years of age, hospitalization rate and hospital mortality. Vaccination does not eliminate pharmacological interventions. ${ }^{16}$

COVID 19 pandemic has created global crisis. Many countries-imposed restriction of the movement of population. This led to economic crisis. Lock down measures cannot be sustained indefinitely. It is necessary to isolate infected population and save others. Removing COVID-19 restrictions is not about returning to the pre pandemic normal but about gradually and cautiously transitioning to a new normal. Many countries have increased their health infrastructure and releasing the restrictions at their own pace. ${ }^{17}$

SARS-CoV-2 pandemic has imposed increased mortality, morbidity among population and also increased unemployment and economic crisis. There are also increased mental health problems and illness due to other diseases which were neglected during the pandemic period. No seasonal pattern was observed in COVID 19 disease. Long term problems of cardiovascular, respiratory, neurological and mental health are seen in many of the survivors and they may reduce longevity and cause premature death. Based on the statistics coronavirus disease is rampant in countries like USA and UK where vaccination is achieved in $75 \%$ of population. ${ }^{18}$ As observed in our study there is no seasonal preponderance of the disease and the increased prevalence of the disease occurred in different seasons in different countries.

Vaccination has a definite positive effect and reduced mortality. Severity of the disease and mortality are high among unvaccinated. ${ }^{19}$ In hospital, mortality rate declined despite the presence of COVID 19 variants in a UK study among Asian Immigrants and they interpreted that relative importance of the variants may change with time. ${ }^{20}$

Mortality statistics among hospitalized COVID patients may not be totally reflective of the situation. Patients dying of coronary artery disease, renal failure, hepatic disease and multi organ failure during the COVID pandemic are reported as non-COVID deaths. In some of these cases COVID 19 has a definite role in aggravation of their existing disease or the inflammatory activity and vascular thrombosis associated with COVID disease might have precipitated death. The deaths occurring after the patient is rendered negative for COVID are also influenced by the continued inflammation of COVID disease. All the negative COVID tests are not truly negative since the RT PCR tests may be negative in the presence of the variants. Post COVID pulmonary fibrosis, continued requirement of oxygen, long COVID syndrome and associated psychological stress and financial loss and loss of employment all contribute to increased mortality among patients having pre-existing disease.

In India, percentage of population having taken both doses of vaccine are only around $32 \%$. Many European countries have achieved a full vaccination for nearly two thirds of their population. Continued viral infections despite vaccination suggests that vaccine alone cannot protect the population but other factors like social distancing, COVID appropriate behaviour, hand washing and hand hygiene, usage of masks in public places may all contribute to reduce the number of new cases. As we have seen in several parts of the world social congregations are always associated with the upsurge of cases.

Since the vaccinations have been found to reduce the mortality, research should focus on the mutations in the spike protein and the new vaccine preparations should be taken into consideration of these variant pathogens for better control of the pandemic.

\section{CONCLUSIONS}

COVID 19 pandemic has challenged the health systems of both the developed and developing world causing considerable mortality and morbidity. Vaccines developed in 2021 gave us a ray of hope. But the variants with new mutations caused sustenance of the pandemic with new infections despite vaccination. The new mutants also caused the routine diagnostic tests ineffective.

Data sharing statement provided by the authors is available with the full text of this article at jemds.com.

Financial or other competing interests: None.

Disclosure forms provided by the authors are available with the full text of this article at jemds.com.

\section{REFERENCES}

[1] Worldometer/corona

[2] Covid World Vaccination Tracker - The New York Times, https://www.nytimes.com > interactive , covidvaccination

[3] Coronavirus (COVID-19) Vaccinations - Statistics and Research https://ourworldindata.org > covidvaccinations

[4] Rapid risk assessment: detection of new SARS-CoV-2 variants related to mink. European Centre for Disease Prevention and Control. 2020; Available from: https://www.ecdc.europa.eu/en/publicationsdata/detection-new-sars-cov-2-variants-mink

[5] Chantal Babb de Villiers (PHG Foundation) Laura Blackburn (PHG Foundation) Sarah Cook (PHG Foundation) Joanna Janus (PHG Foundation)SARS-CoV-2 variants, FIND, Publication date: 11 March 2021.

[6] Volz E, Mishra S, Chand M, et al. Transmission of SARSCoV-2 Lineage B.1.1.7 in England: Insights from linking epidemiological and genetic data. medRxiv 2021. 
[7] Novel variants of SARS-CoV-2 and the impact on diagnostic testing. FIND. 2021 Available from: https://www.finddx.org/covid-19/novel-variants/

[8] Zhang W, Davis BD, Chen SS, et al. Emergence of a novel SARS-CoV-2 variant in Southern California. JAMA 2021;325(13):1324-6.

[9] Risk assessment: SARS-CoV-2 - increased circulation of variants of concern and vaccine rollout in the EU/EEA, 14th update. European Centre for Disease Prevention and Control 2021. Available from: https://www.ecdc.europa.eu/en/publicationsdata/covid-19-risk-assessment-variantsvaccinefourteenth-update-february-2021]

[10] Madhi SA, Baillie V, Cutland CL, et al. Safety and efficacy of the ChAdOx1 nCoV-19 (AZD1222) Covid-19 vaccine against the B.1.351 variant in South Africa. medRxiv 2021.

[11] Investigation of novel SARS-CoV-2 variant: variant of Concern 2020 (technical briefing 1). Public Health England. 2020; Available from: https://www.gov.uk/government/publications/investig ation-of-novel-sars-cov-2-variant-variant-ofconcern20201201

[12] McNally, A. What makes new variants of SARS-CoV-2 concerning is not where they come from, but the mutations they contain. BMJ. 2021; Available from: https://blogs.bmj.com/bmj/2021/02/16/whatmakesnew-variants-of-sars-cov-2-concerning-is-not-wherethey-come-from-but-the-mutations-theycontain/
[13] Brief report: New Variant Strain of SARS-CoV-2 Identified in Travelers from Brazil. National Institute of Infectious Diseases, Japan 2021. Available from: https://www.niid.go.jp/niid/en/2019-ncove/10108covid19-33-en.html.

[14] Singh J, Rahman SA, Ehtesham NZ, et al. SARS-CoV-2 variants of concern are emerging in India. Nat Med 2021;27(7):1131-3.

[15] Alagoz O, Sethi AK, Patterson BW, et al. The impact of vaccination to control COVID-19 burden in the United States: A simulation modeling approach. PLoS One 2021;16(7):e0254456.

[16] Moghadas SM, Vilches TN, Zhang K, et al. The impact of vaccination on COVID-19 outbreaks in the United States. Clin Infect Dis 2021;ciab079.

[17] Han E, Tan MMJ, Eva Turk, Sridhar D, et al. Lessons learnt from easing COVID-19 restrictions: an analysis of countries and regions in Asia Pacific and Europe. The Lancet 2020;396(10261):1525-34.

[18] Cutler DM, Summers LH. The COVID-19 pandemic and the $\$ 16$ trillion virus. JAMA. 2020;324(15):1495-6.

[19] Agrawal U, Katikireddi SV, McCowan C, et al. COVID-19 hospital admissions and deaths after BNT162b2 and ChAd0x1 nCoV-19 vaccinations in 2.57 million people in Scotland (EAVE II): a prospective cohort study. The Lancet 2021;9(12):1439-49.

[20] Gray WK, Navaratnam AV, Day J, et al. Changes in COVID19 in-hospital mortality in hospitalised adults in England over the first seven months of the pandemic: an observational study using administrative data. The Lancet Regional Health-Europe 2021;5:100104. 